\title{
Effectiveness of neuromuscular electrical stimulation for the rehabilitation of moderate-to-severe COPD: a meta-analysis
}

This article was published in the following Dove Press journal:

International Journal of COPD

28 November 2016

Number of times this article has been viewed

\author{
Rong-chang Chen ${ }^{1, *}$ \\ Xiao-ying $\mathrm{Li}^{1, *}$ \\ Li-li Guan' \\ Bing-peng Guo' \\ Wei-liang $\mathrm{Wu}^{\prime}$ \\ Zi-qing Zhou' \\ Ya-ting Huo' \\ Xin Chen $^{2}$ \\ Lu-qian Zhou'
}

'State Key Laboratory of Respiratory

Disease, Guangzhou Institute of Respiratory Disease, First Affiliated

Hospital of Guangzhou Medical

University, ${ }^{2}$ Zhujiang Hospital

of Southern Medical University,

Guangzhou, People's Republic of China

*These authors contributed equally to this work
Correspondence: Lu-qian Zhou State Key Laboratory of Respiratory Disease, Guangzhou Institute of Respiratory Disease, First Affiliated Hospital of Guangzhou Medical University, I5I Yanjiang Road,

Guangzhou, Guangdong 510120, People's

Republic of China

Tel +86 I56 22236759

Fax +86 2083062882

Email zhlx09@163.com
Purpose: Patients with COPD often experience skeletal muscle dysfunction. For those who are unable or unwilling to undertake physical training, neuromuscular electrical stimulation (NMES) may provide an alternative method of rehabilitation. The purpose of this meta-analysis was to investigate the controversial topic of whether this therapy is effective in patients with moderate-to-severe COPD.

Patients and methods: We pooled data from nine trials published between January 9, 2002 and January 4, 2016 across PubMed, Embase, Cochrane Central Register of Controlled Trials, Google Scholar, and relevant websites for randomized controlled trials. In these trials, patients with moderate-to-severe COPD were randomly allocated to receive NMES. Primary outcomes were quadricep strength and exercise capacity. The secondary outcome was health-related quality of life.

Results: We extracted data from 276 patients. NMES contributed to statistically improved quadricep strength (standardized mean difference 1.12, 95\% confidence interval [CI] 0.64-1.59, $\left.I^{2}=54 \% ; P<0.00001\right)$ and exercise capacity, including longer exercise distance (weighted mean difference $51.53,95 \%$ CI $20.13-82.93, I^{2}=90 \% ; P=0.001$ ), and longer exercise endurance (standardized mean difference $1.11,95 \%$ CI $0.14-2.08, P^{2}=85 \% ; P=0.02$ ). There was no significant difference in St George's Respiratory Questionnaire scores (weighted mean difference $-0.07,95 \% \mathrm{CI}-2.44$ to $2.30, I^{2}=56 \% ; P=0.95$ ).

Conclusion: NMES appears an effectual means of enhancing quadricep strength and exercise capacity in moderate-to-severe COPD patients. Further research is demanded to clarify its effect on other outcomes and determine the optimal parameters for an NMES program.

Keywords: neuromuscular electrical stimulation, chronic obstructive pulmonary disease, quadriceps muscle strength, exercise capacity

\section{Introduction}

COPD is a major cause of morbidity and mortality worldwide, and leads to a significant economic and social burden. It is predicted to become the third-leading cause of death in 2020. ${ }^{1-3}$ It is now recognized that COPD is characteristic with inspiratory muscle fatigue and skeletal muscle deconditioning, which is associated with reduced quality of life and premature mortality. ${ }^{4}$

It has been well established that physical and respiratory muscle training is beneficial for patient rehabilitation in COPD, and physical training especially is considered one of the best treatments available for enhancing limb-muscle function. ${ }^{1,5-7}$ A recent study showed that physical training may prevent cognitive decline and associated comorbidities in male patients with COPD. ${ }^{8}$ Indeed, advanced-stage COPD 
patients may be too frail to tolerate physical training because of intense breathlessness at rest or on minimum exertion. ${ }^{9}$ Neuromuscular electrical stimulation (NMES) is emerging as a new rehabilitation modality that does not evoke dyspnea to obtain a benefit in patients who are unable to participate in a traditional rehabilitation program. Also, it has been intensively applied in healthy people and athletes for curative care rehabilitation and preventing deconditioning. ${ }^{10}$

Previous studies ${ }^{11-20}$ have not reached consistent conclusions, and a meta-analysis ${ }^{21}$ published in 2014 draw equivocal findings on the effects of NMES in moderate-to-severe COPD. Also, there have been several larger-scale and higher-quality trials ${ }^{22-28}$ published in recent years; therefore, we performed a meta-analysis to investigate the effects of NMES in these patients.

\section{Patients and methods}

\section{Search strategy}

We searched PubMed, Embase, Cochrane Central Register of Controlled Trials, Google Scholar, and relevant websites to detect randomized controlled trials (RCTs) published up to June 2016 in accordance with Preferred Reporting Items for Systematic Reviews and Meta-Analyses guidelines. ${ }^{29-31}$ Search terms were "chronic obstructive pulmonary disease", "neuromuscular electrical stimulation", and their corresponding Medical Subject Headings terms. Studies were filtered for human subjects and RCTs; only published trials written in English were included. We excluded studies of comparisons other than NMES and those with duplicated data.

\section{Study selection}

The inclusive selection criteria were RCTs investigating the role of NMES in patients with moderate-to-severe COPD, predefined program of NMES applied to the lower limbs, unstimulated or other treatment (ie, sham stimulation) defined as the control group, and primary outcome quadricep strength and exercise capacity, defined as moving distance and endurance time. The secondary outcome was St George's Respiratory Questionnaire (SGRQ) score. ${ }^{32}$ The criteria complied with PICO (patient/problem/population, intervention, comparison/ control/comparator, outcomes) principles. For articles reported in more than two publications, only the full version was used for meta-analysis. Abstracts published merely in academic conferences or website materials were excluded.

\section{Data extraction}

Two investigators (XL and LG) assessed the title or abstract for eligibility. In cases of discordance, a third investigator (BG) participated in discussion to reach a final consensus.
For studies that met the inclusion criteria, full papers were obtained for further analysis. Information related to trial design, characteristics of the patients, and relevant results were noted according to a redesigned form. We recorded first author, year, patient numbers, age, sex, body mass index, forced expiratory volume in 1 second, stage of COPD, experimental and control interventions (ie, type of intervention, pulse duration, pulse frequency, duty cycle, intensity of current used, training intensity, session time, and duration in weeks), and outcome parameters and their results. When data were insufficient or inapplicable, we attempted to contact the authors by email or used a formula ${ }^{29-31}$ to convert into available data.

\section{Outcomes}

Outcomes were assigned to categories according to comparable features and representation. The preestablished primary outcome was quadricep strength and exercise capacity. Quadricep strength was measured using various methods, including isokinetic quadricep peak torque, maximum voluntary contraction, and author-defined score. Exercise capacity was primarily 6 -minute walk test (6MWT), ${ }^{33}$ shuttlewalk test (SWT), ${ }^{34,35}$ and constant-work test (CWT), ${ }^{36}$ and we pooled exercise distance and endurance time from these tests. The prespecified secondary outcome was health-related life quality measured with the SGRQ.

\section{Data analysis}

Meta-analyses were done with RevMan 5.3 software (Cochrane Collaboration, London, UK). Weighted mean difference (WMD) or standardized mean difference (SMD) with $95 \%$ confidence interval (CI) was considered for summary statistics and derived for the comparison of NMES with other rehabilitation methods. SMD was utilized when studies reported different units or scales for the outcome. To account for between-trial differences, we used mixed-effect modeling with random effect for parameters of interest, because of the anticipated heterogeneity in NMES methodology, including different stimulating parameters, different durations of therapy, and diverse study designs and study populations. Heterogeneity across studies was tested using the $I^{2}$ statistic: $I^{2}$ values of less than $25 \%, 25 \%-50 \%$, or more than $50 \%$ indicated low, moderate, or high heterogeneity, respectively. ${ }^{37}$ Potential heterogeneity sources were identified by sensitivity analyses conducted by eliding one study successively and comparing the influence of each study on the overall pooled estimate if $I^{2}>50 \%$. Funnel plots were not constructed, owing to the limited number (below 10) of studies included in the analysis. For another primary outcome of exercise capacity, subgroup analyses were performed based 
on methods of exercise test: 6MWT, SWT, and CWT. Data are presented as means ( \pm standard deviation), and a twotailed $P$-value $<0.05$ was considered statistically significant. The overall treatment effect was compared with its minimum clinically important difference (MCID).

\section{Evaluation of bias and quality assessment}

Freedom from bias was evaluated for each study in accordance with the basis of methodological domains: ${ }^{29-31}$ adequacy of random-sequence generation and allocation concealment, attrition bias, reporting bias, and other biases. Two authors (BG and XL) reviewed all the studies and assigned a value of "high", "low", or "unclear".

The methodological quality of the identified trials was scored independently using the GRADE (Grades of Recommendation, Assessment, Development, and Evaluation) system. ${ }^{38,39}$ The GRADE system classifies four levels - high, moderate, low, and very low - in terms of the quality of evidence. This approach for book reviews on the quality of the evidence is based on five items: study limitations, inconsistency of the results, indirectness of evidence, imprecision, and reporting bias. For purpose of assessing the reliability of the grade, the quality classification of the selected articles was independently assessed by two investigators, with divergences resolved by a third investigator (GB).

\section{Results}

\section{Articles retrieved and characteristics of included trials}

Primary literature searches included 370 articles, of which 62 remained after exclusion of duplicates. Following screening of titles and abstracts, 20 studies were removed owing to unrelated content; 17 studies were not RCTs. Of 25 full-text citations, nine studies with 276 participants fulfilled inclusive criteria to be reviewed. For papers excluded from this analysis, eight were due to study design, ${ }^{10,13,15,16,40-43}$ four were due to the fact that stimulation was acupuncture, ${ }^{44-47}$ three ${ }^{11,24,28}$ had insufficient or inapplicable data, and one ${ }^{25}$ reported on the same group of participants as in another paper. ${ }^{26}$ Figure 1 describes the different phase of the search process. The pooled articles were published between 2002 and 2016. By pooling data from these trials, 139 were assigned to NMES (intervention population) and 137 assigned to the control population. The characteristics of participants, interventions, and the main results extracted in corresponding studies are shown in Table 1. NMES was applied to the quadriceps and

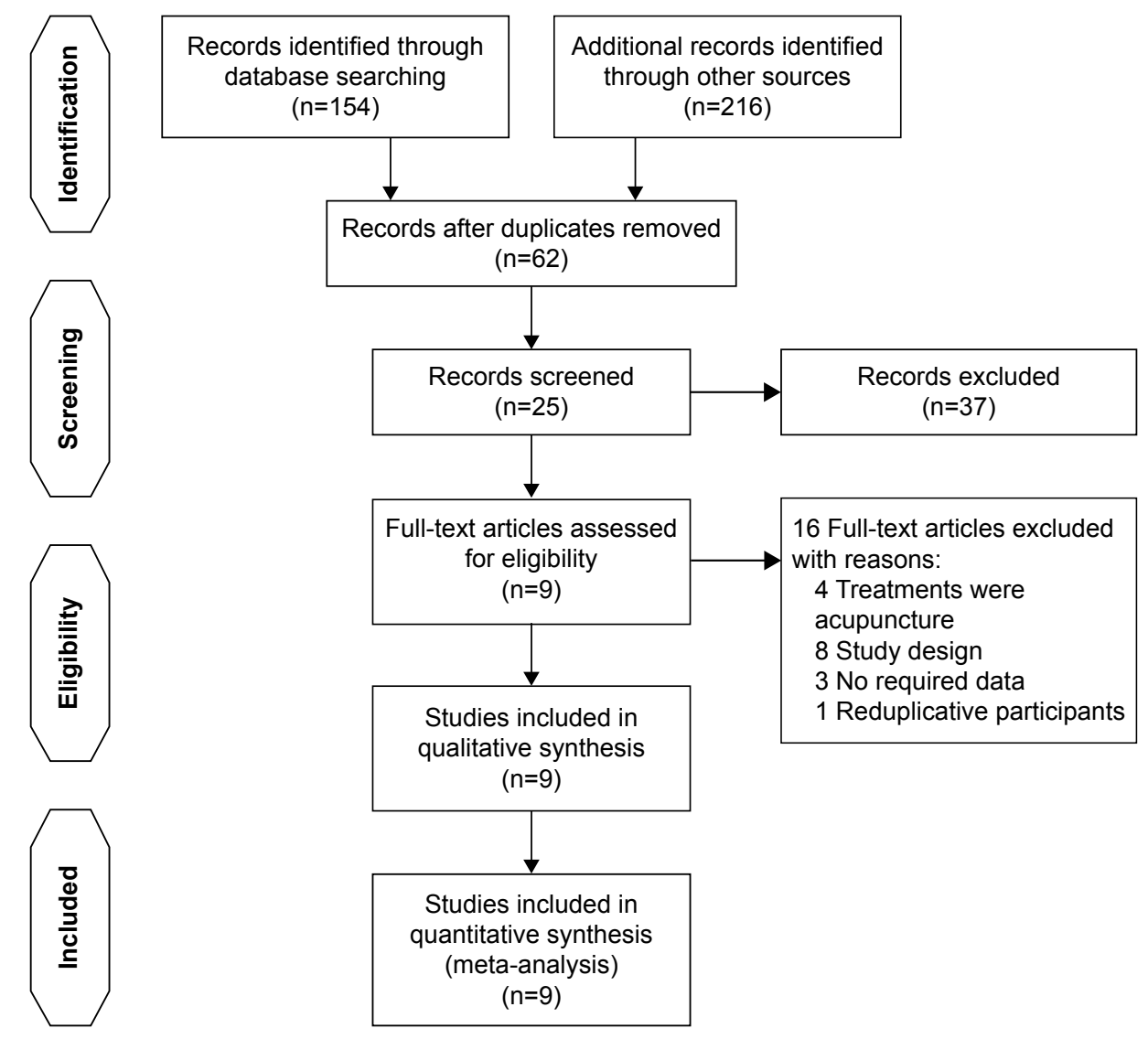

Figure I Study-selection flowchart. 
Table I Characteristics of randomized controlled trials included in the meta-analysis

\begin{tabular}{|c|c|c|c|c|c|c|c|}
\hline Study, year & $\begin{array}{l}\text { Number of } \\
\text { patients }(\mathrm{m} / \mathrm{f})\end{array}$ & Grade & Stage & $\begin{array}{l}\text { BMI, kg/m² } \\
\text { (NMES/sham) }\end{array}$ & $\begin{array}{l}\text { Age, years } \\
\text { (NMES/sham) }\end{array}$ & $\begin{array}{l}\text { FEV } \% \\
\text { (NMES/sham) }\end{array}$ & $\begin{array}{l}\text { Study } \\
\text { group (n) }\end{array}$ \\
\hline $\begin{array}{l}\text { Bourjeily-Habr } \\
\text { et al, },^{19} 2002\end{array}$ & $18(10 / 8)$ & $\begin{array}{l}\text { Moderate- } \\
\text { to-severe }\end{array}$ & Stable COPD & $26.2 / 27.1$ & $58.5 / 61.5$ & $35.6 / 40.7$ & NMES (9); control (9) \\
\hline $\begin{array}{l}\text { Neder et al, }{ }^{20} \\
2002\end{array}$ & $15(9 / 6)$ & $\begin{array}{l}\text { Moderate- } \\
\text { to-severe }\end{array}$ & Stable COPD & $24.8 / 25.6$ & $66.6 / 65$ & $38 / 39.5$ & NMES (9); control (6) \\
\hline $\begin{array}{l}\text { Zanotti et al, }{ }^{18} \\
2003\end{array}$ & $24(17 / 7)$ & NA & $\begin{array}{l}\text { Stable COPD } \\
\text { in ICU }\end{array}$ & $24.5 / 22.4$ & $66.2 / 64.5$ & NA & $\begin{array}{l}\text { NMES + UR (I2); } \\
\text { UR (I2) }\end{array}$ \\
\hline $\begin{array}{l}\text { Vivodtzev et al, }{ }^{17} \\
2006\end{array}$ & $17(|| / 6)$ & Severe & Stable COPD & $18.1 / 18$ & $59 / 68$ & $27 / 34$ & NMES + UR (9); UR (8) \\
\hline $\begin{array}{l}\text { Vivodtzev et al, }{ }^{12} \\
2012\end{array}$ & $20(13 / 7)$ & Severe & Stable COPD & $21 / 21$ & $70 / 68$ & $34 / 30$ & NMES (I2); sham (8) \\
\hline $\begin{array}{l}\text { Sillen et al, }{ }^{25,26} \\
2014\end{array}$ & $81(43 / 38)$ & Severe & Stable COPD & $24.1 / 24.9$ & $64.4 / 64$ & $33 / 33$ & $\begin{array}{l}\text { HF-NMES (4I); } \\
\text { strength training (40) }\end{array}$ \\
\hline $\begin{array}{l}\text { Vieira et al, }{ }^{27} \\
2014\end{array}$ & $20(20 / 0)$ & $\begin{array}{l}\text { Moderate- } \\
\text { to-severe }\end{array}$ & Stable COPD & $27.47 / 27.6$ & $56.3 / 56.4$ & $36.5 / 39.6$ & NMES (I I); control (9) \\
\hline $\begin{array}{l}\text { Tasdemir et al, }{ }^{23} \\
2015\end{array}$ & $27(24 / 3)$ & $\begin{array}{l}\text { Moderate- } \\
\text { to-severe }\end{array}$ & Stable COPD & $25.1 / 27.4$ & $62.1 / 62.9$ & $29 / 42.5$ & $\begin{array}{l}\text { NMES + cPR (I3); } \\
\text { Sham + cPR (I4) }\end{array}$ \\
\hline $\begin{array}{l}\text { Maddocks et al, }{ }^{22} \\
2016\end{array}$ & $52(2|/ 3|)$ & Severe & Stable COPD & $25.7 / 27.8$ & $70 / 69$ & $30.8 / 30.7$ & $\begin{array}{l}\text { NMES (25); } \\
\text { placebo (27) }\end{array}$ \\
\hline
\end{tabular}

Notes: Data shown are mean \pm SD unless otherwise indicated. (\%), percentage predicted value.

Abbreviations: BMI, body mass index; $\mathrm{FEV}_{1}$, forced expiratory volume in I second; NMES, neuromuscular electrical stimulation; NA, not available; COPD, chronic obstructive pulmonary disease; UR, usual rehabilitation; HF-NMES, high frequency neuromuscular electrical stimulation; SWT, shuttle-walk test; 6MWT, 6-minute walk test; MVC, maximum voluntary contraction; SGRQ, St George's Respiratory Questionnaire; RCT, randomized controlled trial; ALMs, active limb mobilizations; M, male; F, female; ICU, intensive care unit; cPR, comprehensive pulmonary rehabilitation; MRC, Medical Research Council scale; I, intensive.

also to accessory respiratory muscles. ${ }^{27}$ Stimulation-pulse duration was 250-400 $\mu \mathrm{s}$, and stimulation frequency ranged from 8 to $120 \mathrm{~Hz}$. Intensities ranged from 10 to $100 \mathrm{~mA}$, and were gradually increased throughout the entire stimulation according to the patient's individual tolerance.

\section{Risk-of-bias assessment and quality assessment}

The risk-of-bias among studies is shown in Figure 2. Inadequate description of data on the randomization protocol or blinding strategy was reported in most of the RCTs, except for two, ${ }^{22,26}$ which may have led to "unclear risk of bias". On the other hand, quality-assessment items are presented in Figures 3 and 4. Evidence based on RCTs is assumed to be high-quality evidence, unless there are some issues, which may reduce confidence in the study. These included limitations of study design, inconsistency, indirectness, imprecision, and publication bias. ${ }^{48}$ For the pooled studies, we kept the original conclusion if the study quality was high and there was no violation of these criteria. ${ }^{49}$ 


\begin{tabular}{|c|c|c|c|c|}
\hline \multicolumn{3}{|l|}{ NMES group } & \multirow[t]{2}{*}{ Control group } & \multirow[t]{2}{*}{ Study design } \\
\hline Training protocol & NMES parameters & Outcomes & & \\
\hline $\begin{array}{l}6 \text { week } \times 3 \text { sessions/week; } \\
20 \mathrm{~min} / \text { per session }\end{array}$ & $\begin{array}{l}\text { Frequency: } 50 \mathrm{~Hz} \text {; pulse } \\
\text { duration: } \mathrm{NA} \text {; intensity: } \\
56.7-95 \mathrm{~mA} \text {; duty cycle: } \\
0.2 \mathrm{~s} \text { on/l.3 seconds off }\end{array}$ & $\begin{array}{l}\text { SWT; quadriceps strength } \\
\text { (isokinetic peak torque) }\end{array}$ & $\begin{array}{l}\text { Control: sham NMES (same } \\
\text { instruction and electrode } \\
\text { position, but no stimulation) }\end{array}$ & RCT, double-blind \\
\hline $\begin{array}{l}6 \text { week } \times 5 \text { sessions/week; } \\
15 \text { min in the Ist week and } \\
30 \text { min thereafter }\end{array}$ & $\begin{array}{l}\text { Frequency: } 50 \mathrm{~Hz} \text {; pulse } \\
\text { duration: } 300-400 \text { us; intensity: } \\
\text { I0-20 mA to } 100 \mathrm{~mA} \text {; duty } \\
\text { cycle: } 2 \mathrm{~s} \text { on } / 18 \mathrm{~s} \text { off to } 10 \mathrm{~s} \\
\text { on } / 30 \mathrm{~s} \text { off }\end{array}$ & $\begin{array}{l}\text { Quadriceps strength (peak } \\
\text { torque), exercise endurance }\end{array}$ & Usual care & RCT, double-blind \\
\hline $\begin{array}{l}4 \text { week } \times 5 \text { sessions/week; } \\
30 \mathrm{~min} / \text { per session }\end{array}$ & $\begin{array}{l}\text { Frequency: } 8-35 \mathrm{~Hz} \text {; pulse } \\
\text { duration: } 250-350 \text { us; } \\
\text { intensity: NA; duty cycle: NA }\end{array}$ & Peripheral muscle strength & ALM & RCT, double-blind \\
\hline $\begin{array}{l}4 \text { week } \times 4 \text { sessions/week; } \\
30 \mathrm{~min} / \text { per session }\end{array}$ & $\begin{array}{l}\text { Frequency: } 35 \mathrm{~Hz} \text {; pulse } \\
\text { duration: } 400 \mathrm{us} \text {; intensity: } \\
\text { max tolerable }(2 \mathrm{I}-46 \mathrm{~mA}) \text {; } \\
\text { duty cycle: } 47 \%\end{array}$ & $\begin{array}{l}\text { Quadriceps strength (MVC); } \\
6 \mathrm{MWT} \text {; dyspnoea }\end{array}$ & 4 days per week of ALMs & RCT, single-blind \\
\hline $\begin{array}{l}6 \text { week } \times 5 \text { sessions/week; } \\
35 \text { min of stimulation of the } \\
\text { quadriceps followed by } 25 \mathrm{~min} \\
\text { of stimulation of the calf }\end{array}$ & $\begin{array}{l}\text { Frequency: } 50 \mathrm{~Hz} \text {; pulse } \\
\text { duration: } 400 \mathrm{us} \text {; intensity: } \\
\text { max tolerable }(20-31 \mathrm{~mA}) \text {; } \\
\text { duty cycle: } 2 \mathrm{~s} \text { on } / 16 \mathrm{~s} \text { off }\end{array}$ & $\begin{array}{l}\text { Quadriceps strength; } \\
\text { exercise endurance; SWT; } \\
\text { dyspnoea }\end{array}$ & $\begin{array}{l}\text { Sham: Frequency: } 5 \mathrm{~Hz} \text {, } \\
\text { pulse duration }=100 \text { us }\end{array}$ & RCT, double-blind \\
\hline $\begin{array}{l}8 \text { week } \times 5 \text { sessions } / \text { week; } \\
18 \mathrm{~min} / \text { per session }\end{array}$ & $\begin{array}{l}\text { Frequency: } 75 \mathrm{~Hz} \text {; pulse } \\
\text { duration: } 400 \text { us intensity: max } \\
\text { tolerable; duty cycle: NA }\end{array}$ & $\begin{array}{l}\text { Quadriceps muscle strength } \\
\text { (isokinetic quadriceps } \\
\text { muscle strength); 6MWT; } \\
\text { exercise endurance; } \\
\text { dyspnoea; SGRQ }\end{array}$ & Strength training & RCT, single-blind \\
\hline $\begin{array}{l}8 \text { week } \times 5 \text { sessions } / \text { week; } \\
60 \mathrm{~min} / \text { per session }\end{array}$ & $\begin{array}{l}\text { Frequency: } 50 \mathrm{~Hz} \text {; pulse } \\
\text { duration: } 300-400 \text { us; intensity: } \\
\text { max tolerable (I5-20 mA } \\
\text { to } 100 \mathrm{~mA}) \text {; duty cycle: } 2 \mathrm{~s} \\
\text { on } / 18 \mathrm{~s} \text { off to } 10 \mathrm{~s} \text { on } / 30 \mathrm{~s} \text { off }\end{array}$ & $\begin{array}{l}\text { 6MWT; dyspnoea; exercise } \\
\text { endurance; SGRQ }\end{array}$ & $\begin{array}{l}\text { Sham NMES (same } \\
\text { instruction and electrode } \\
\text { position, but no stimulation) }\end{array}$ & RCT, double-blind \\
\hline $\begin{array}{l}10 \text { week } \times 2 \text { sessions } / \text { week; } \\
20 \mathrm{~min} / \text { per session }\end{array}$ & $\begin{array}{l}\text { Frequency: } 50 \mathrm{~Hz} \text {; pulse } \\
\text { duration: } 300 \text { us; intensity: } \\
\text { max individual tolerance } \\
(29.43-35.8 \mathrm{I} \mathrm{mA}) \text {; duty cycle: } \\
10 \mathrm{~s} \text { on } / 20 \mathrm{~s} \text { off }\end{array}$ & $\begin{array}{l}\text { SWT; dyspnoea; quadriceps } \\
\text { muscle strength; exercise } \\
\text { endurance; MRC; SGRQ }\end{array}$ & $\begin{array}{l}\text { cPR: mainly exercise } \\
\text { training Sham: NMES } \\
\text { (Intensive: } 5 \mathrm{~mA} \text { ), } \\
\text { insufficient to elicit a tetanic } \\
\text { muscular contraction }\end{array}$ & RCT, double-blind \\
\hline $\begin{array}{l}6 \text { week } \times 7 \text { sessions/week; } \\
30 \mathrm{~min} / \text { per session }\end{array}$ & $\begin{array}{l}\text { Frequency: } 50 \mathrm{~Hz} \text {; pulse } \\
\text { duration: } 350 \text { us; intensity: max } \\
\text { tolerable; duty cycle: } 2 \mathrm{~s} \\
\text { on } / 15 \mathrm{~s} \text { off to } 10 \mathrm{~s} \text { on } / 15 \mathrm{~s} \text { off }\end{array}$ & $\begin{array}{l}\text { 6MWT; quadriceps muscle } \\
\text { strength (MVC); SGRQ }\end{array}$ & $\begin{array}{l}\text { Placebo NMES (I: 0-20 mA), } \\
\text { insufficient to elicit a tetanic } \\
\text { muscular contraction }\end{array}$ & RCT, double-blind \\
\hline
\end{tabular}

\section{Primary outcomes}

Results from nine RCTs ( $\mathrm{n}=276)$ were obtained to assess the effects of NMES on patients with moderate-to-severe COPD. Aggregate analyses showed that the application of NMES was linked to significantly enhanced quadricep strength (SMD $1.12,95 \%$ CI $0.64-1.59, I^{2}=54 \% ; P<0.00001$ ) (Figure 5). There was also a benefit of NMES in improving exercise capacity, evaluated as longer exercise distance traveled $\left(\right.$ WMD 51.53, 95\% CI 20.13-82.93, $I_{\text {overall }}=90 \%, I_{\text {subgroup }}$ differences $=0 ; P=0.001$ ) (Figure 6 ) or longer exercise endurance time (SMD 1.11, 95\% CI 0.14-2.08, $I_{\text {overall }}^{2}=85 \%, I_{\text {subgroup }}^{2}$ differences $=81.6 \% ; P=0.02$ ) (Figure 7). We failed to draw funnel plots to explore the potential source of heterogeneity, because the number of RCTs included was fewer than 10 . We further carried out subgroup analyses to investigate the impact of NMES on exercise capacity with different exercise tests. For 6MWT, walking distance was significantly improved (WMD $37.27,95 \%$ CI $\left.31.82-42.73, I^{2}=0 ; P<0.00001\right)$. For CWT, endurance time also increased significantly (SMD 1.78, $95 \%$ CI $\left.1.16-2.40, P^{2}=35 \% ; P<0.00001\right)$. For SWT, there 


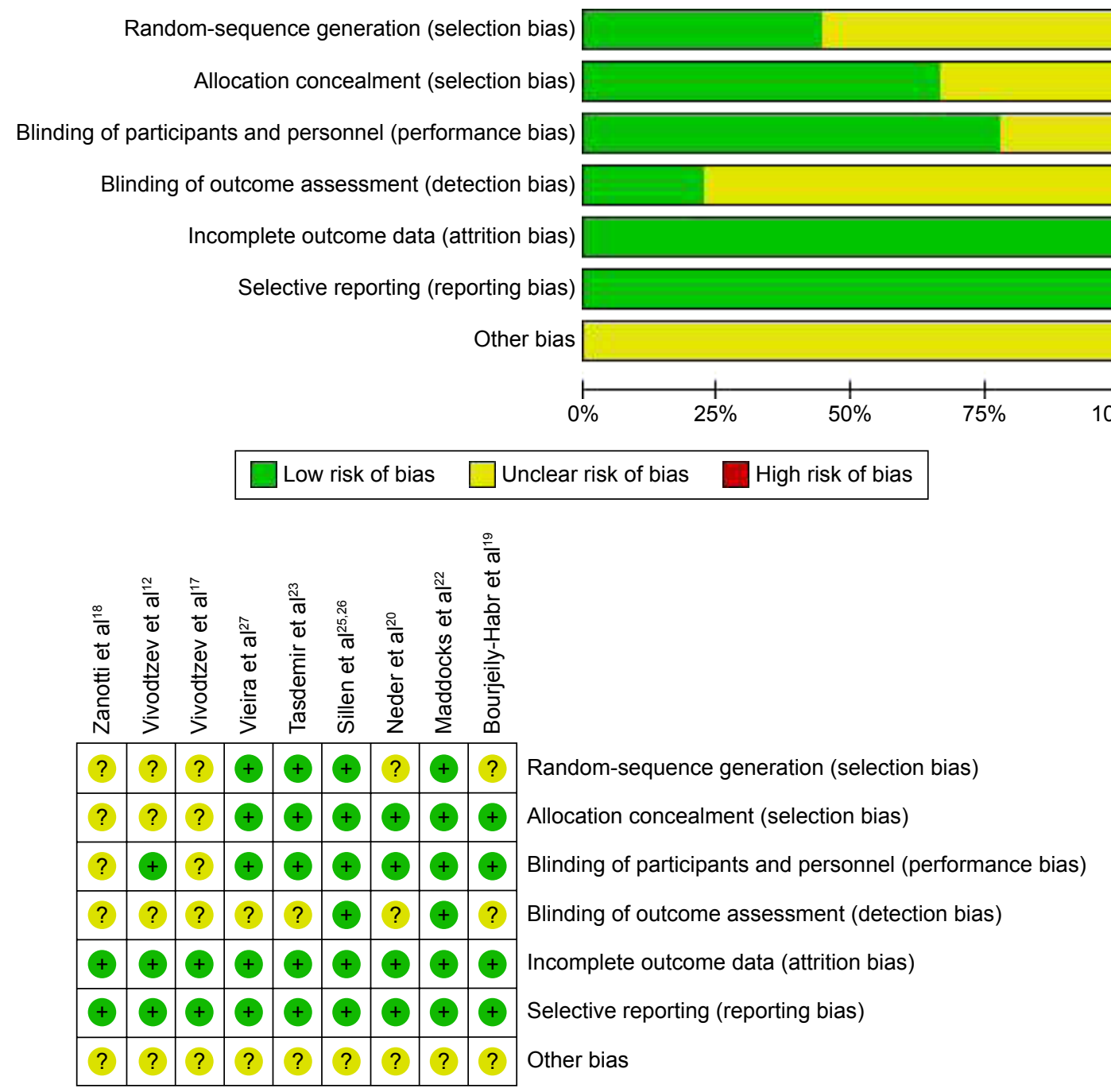

Figure 2 Risk-of-bias analysis.

was no significant improvement in distance (WMD 68.06, $95 \% \mathrm{CI}-50.7$ to $186.83, P=96 \% ; P=0.26$ ) or endurance time (SMD $0.28,95 \% \mathrm{CI}-0.82$ to $1.38, I^{2}=70 \% ; P=0.62$ ).

\section{Secondary outcomes}

For health-related quality of life, the results demonstrated that NMES did not improve SGRQ scores (WMD -0.07, 95\% CI -2.44 to $2.30, I^{2}=56 \% ; P=0.95$ ) (Figure 8 ). We did not perform sensitivity analyses to explore potential sources of heterogeneity, because only three RCTs were included.

\section{Discussion}

This pooled analysis of data from nine RCTs indicated several meaningful findings for NMES for severe COPD. The main findings of this meta-analysis are that NMES improved patients' quadricep strength and exercise capacity, particularly across a range of the subgroups, but no statistically significant improvement in the degree of healthrelated quality of life.

To our knowledge, our meta-analysis involved the largest

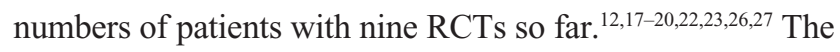
strength and quality of this meta-analysis should be better than those with fewer patients and RCTs reported in the literature. Compared with the equivocal results of Pan et al's review ${ }^{21}$ on the efficacy of NMES, our conclusion is contradictory. On the premise of including larger numbers and most high-quality trials, we performed subgroup analysis to classify the evaluation methodology on the outcomes. In addition, we use the GRADE system for the meta-analysis, which has advantages over other rating systems ${ }^{48}$ for evaluating the methodological quality of pooled trials. As such, we consider our meta-analysis more convincing and providing evidence in favor of NMES.

Quadricep strength was enhanced significantly, as demonstrated by pooled data on isokinetic quadricep peak torque 
Quadriceps muscle strengh for moderate to severe COPD

Patient or population: patients with moderate to severe COPD

Settings:

Intervention: Quadriceps muscle strengh

\begin{tabular}{|c|c|c|c|c|c|}
\hline \multirow[t]{3}{*}{ Outcomes } & \multicolumn{2}{|c|}{ Illustrative comparative risks ${ }^{*}(95 \% \mathrm{Cl})$} & \multirow{3}{*}{$\begin{array}{l}\text { Relative effect No of Participants } \\
\begin{array}{ll}(95 \% \mathrm{Cl}) & \text { (studies) }\end{array}\end{array}$} & \multirow{3}{*}{$\begin{array}{l}\text { Quality of the } \\
\text { evidence } \\
\text { (GRADE) }\end{array}$} & \multirow[t]{3}{*}{ Comments } \\
\hline & Assumed risk & Corresponding risk & & & \\
\hline & Control & Quadriceps muscle strengh & & & \\
\hline $\begin{array}{l}\text { quadriceps muscle } \\
\text { strengh } \\
\text { Follow-up: } 14 \text { years }\end{array}$ & & $\begin{array}{l}\text { The mean quadriceps muscle strengh in the intervention } \\
\text { groups was } \\
\mathbf{1 . 0 6} \text { standard deviations higher } \\
(0.62 \text { to } 1.49 \text { higher) }\end{array}$ & $\begin{array}{l}223 \\
\text { (7 studies) }\end{array}$ & $\begin{array}{l}\oplus \oplus \oplus \oplus \\
\text { high }\end{array}$ & SMD 1.06 ( 0.62 to 1.49$)$ \\
\hline
\end{tabular}

:The basis for the assumed risk (e.g. the median control group risk across studies) is provided in footnotes. The corresponding risk (and its $95 \%$ confidence interval) is based on the assumed risk in the comparison group and the relative effect of the intervention (and its $95 \% \mathrm{Cl}$ ).

Exercise distance for moderate to severe COPD

Patient or population: patients with moderate to severe COPD

Settings:

Intervention: Exercise distance

\begin{tabular}{|c|c|c|c|c|c|}
\hline \multirow[t]{3}{*}{$\overline{\text { Outcomes }}$} & \multicolumn{2}{|c|}{ Illustrative comparative risks ${ }^{*}(95 \% \mathrm{Cl})$} & \multirow{3}{*}{$\begin{array}{l}\text { Relative effect } \\
(95 \% \mathrm{CI})\end{array}$} & \multirow{3}{*}{$\begin{array}{l}\text { No of Participants } \\
\text { (studies) }\end{array}$} & \multirow{3}{*}{$\begin{array}{l}\text { Quality of the evidence Comments } \\
\text { (GRADE) }\end{array}$} \\
\hline & Assumed risk & Corresponding risk & & & \\
\hline & Control & Exercise distance & & & \\
\hline $\begin{array}{l}\text { Distance subgroup } \\
\text { Follow-up: } 10 \text { years }\end{array}$ & & $\begin{array}{l}\text { The mean distance subgroup in the intervention groups was } \\
46.97 \text { higher } \\
\text { (20.15 to } 73.79 \text { higher) }\end{array}$ & & $\begin{array}{l}251 \\
\text { (8 studies) }\end{array}$ & $\begin{array}{l}\oplus \oplus \oplus \oplus \\
\text { high }\end{array}$ \\
\hline Distance subgroup - 6MWT & & $\begin{array}{l}\text { The mean distance subgroup - } 6 \mathrm{mwt} \text { in the intervention groups } \\
\text { was } \\
36.7 \text { higher } \\
\text { ( } 31.31 \text { to } 12.05 \text { higher) }\end{array}$ & & $\begin{array}{l}186 \\
(5)\end{array}$ & \\
\hline Distance subgroup - SWT & & $\begin{array}{l}\text { The mean distance subgroup - } \mathbf{s w t} \text { in the intervention groups } \\
\text { was } \\
68.06 \text { higher } \\
\text { ( } 50.7 \text { lower to } 186.83 \text { higher) }\end{array}$ & & $\begin{array}{l}65 \\
(3)\end{array}$ & \\
\hline
\end{tabular}

'The basis for the assumed risk (e.g. the median control group risk across studies) is provided in footnotes. The corresponding risk (and its $95 \%$ confidence interval) is based on the assumed risk in the comparison group and the relative effect of the intervention (and its $95 \% \mathrm{Cl}$ ).

\section{Exercise endurance time for moderate to severe COPD \\ Patient or population: patients with moderate to severe COPD}

Settings:

Intervention: Exercise endurance time

\begin{tabular}{|c|c|c|c|c|c|}
\hline \multirow[t]{3}{*}{ Outcomes } & \multirow{2}{*}{\multicolumn{2}{|c|}{$\begin{array}{l}\text { IIlustrative comparative risks }{ }^{*}(95 \% \mathrm{Cl}) \\
\text { Assumed risk Corresponding risk }\end{array}$}} & \multirow{3}{*}{ 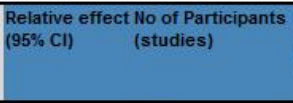 } & \multirow{3}{*}{$\begin{array}{l}\text { Quality of the } \\
\text { evidence } \\
\text { (GRADE) }\end{array}$} & \multirow[t]{3}{*}{ Comments } \\
\hline & & & & & \\
\hline & Control & Exercise endurance time & & & \\
\hline $\begin{array}{l}\text { Endurance time subgroup } \\
\text { Follow-up: } 13 \text { years }\end{array}$ & & $\begin{array}{l}\text { The mean endurance time subgroup in the intervention groups } \\
\text { was } \\
\mathbf{1 . 1 4} \text { standard deviations higher } \\
\text { ( } 0.32 \text { to } 1.96 \text { higher) }\end{array}$ & $\begin{array}{l}179 \\
\text { (6 studies) }\end{array}$ & $\begin{array}{l}\oplus \oplus \oplus \oplus \\
\text { high }\end{array}$ & $\operatorname{SMD} 1.14(0.32$ to 1.96$)$ \\
\hline $\begin{array}{l}\text { Endurance time subgroup - } \\
\text { CWT }\end{array}$ & & $\begin{array}{l}\text { The mean endurance time subgroup - CWT in the intervention } \\
\text { groups was } \\
1.71 \text { standard deviations higher } \\
\text { (1.19 to } 2.22 \text { higher) }\end{array}$ & $\begin{array}{l}132 \\
(4)\end{array}$ & & SMD 1.71 (1.19 to 2.22 ) \\
\hline $\begin{array}{l}\text { Endurance time subgroup - } \\
\text { SWT }\end{array}$ & & $\begin{array}{l}\text { The mean endurance time subgroup - SWT in the intervention } \\
\text { groups was } \\
0.28 \text { standard deviations higher } \\
\text { ( } 0.82 \text { lower to } 1.38 \text { higher) }\end{array}$ & $\begin{array}{l}47 \\
(2)\end{array}$ & & $\begin{array}{l}\text { SMD } 0.28(-0.82 \text { to } \\
1.38)\end{array}$ \\
\hline
\end{tabular}

*The basis for the assumed risk (e.g. the median control group risk across studies) is provided in footnotes. The corresponding risk (and its $95 \%$ confidence interval) is based on the assumed risk in the comparison group and the relative effect of the intervention (and its $95 \% \mathrm{Cl}$ ).

Cl: Confidence interval

GRADE Working Group grades of evidence

High quality: Further research is very unlikely to change our confidence in the estimate of effect.

Moderate quality: Further research is likely to have an important impact on our confidence in the estimate of effect and may change the estimate.

Low quality: Further research is very likely to have an important impact on our confidence in the estimate of effect and is likely to change the estimate.

Very low quality: We are very uncertain about the estimate.

Figure 3 Quality assessment of quadricep strength and exercise capacity.

Abbreviations: SMD, standardized mean difference; CWT, constant-work test; SWT, shuttle-walk test; 6MWT, 6-minute walk test.

in three trials, ${ }^{19,20,25,26}$ maximum voluntary contraction in two studies ${ }^{17,22}$ and author-defined score of a seventh report (Figure 5). ${ }^{18}$ Compared with Pan et al's review, ${ }^{21}$ we included more methods of evaluation of quadricep strength and highimpact articles ${ }^{22,26}$ published shortly after Pan et al's paper. The baseline level of impairment of peripheral muscle function may have important impact on the outcome of NMES. As subjects with varying degrees of impairment of peripheral function were included in the study reports, we included only reports with peripheral muscle weakness. The inconsistent inclusion criteria would have contributed to high heterogeneity. The severity of COPD may also have an impact on the effects of NMES. In this meta-analysis, we focused on COPD patients with moderate-to-severe flow limitation. The study by Napolis et a $\mathrm{l}^{15}$ was excluded, because it included COPD patients with low-level flow limitation. Studies including patients with acute exacerbations of COPD were also excluded, as they might have greater improvement, as suggested by the 


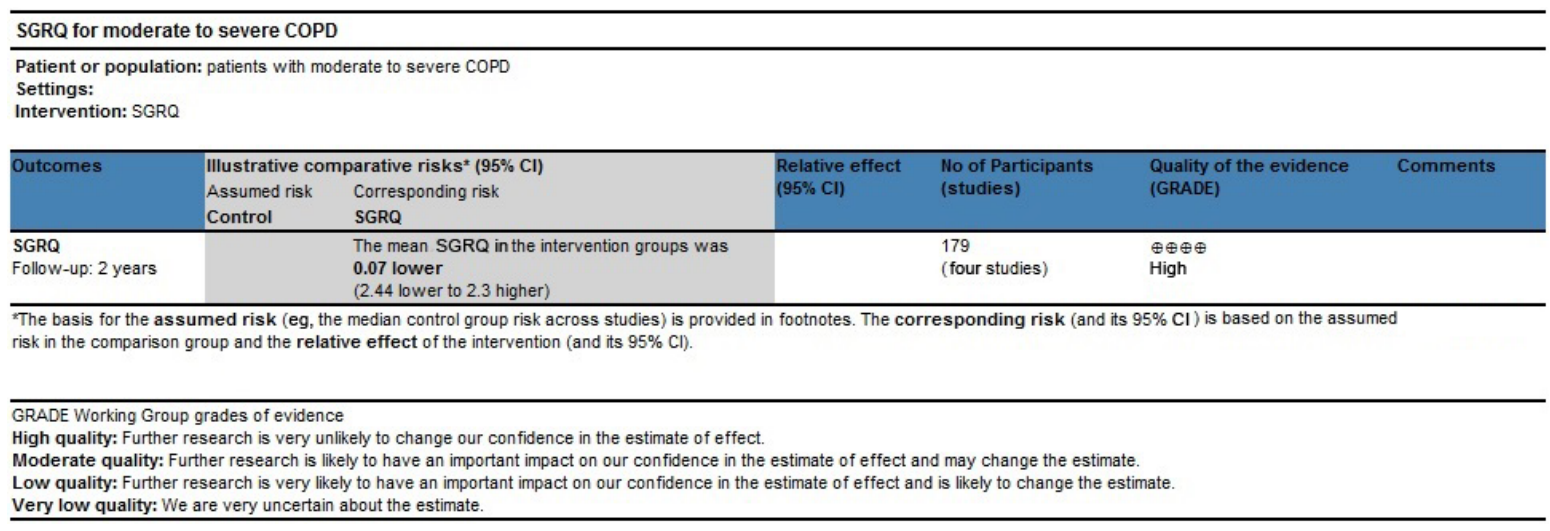

Figure 4 Quality assessment of SGRQ.

Abbreviations: SGRQ, St George's Respiratory Questionnaire; Cl, confidence interval; GRADE, Grades of Recommendation, Assessment, Development, and Evaluation.

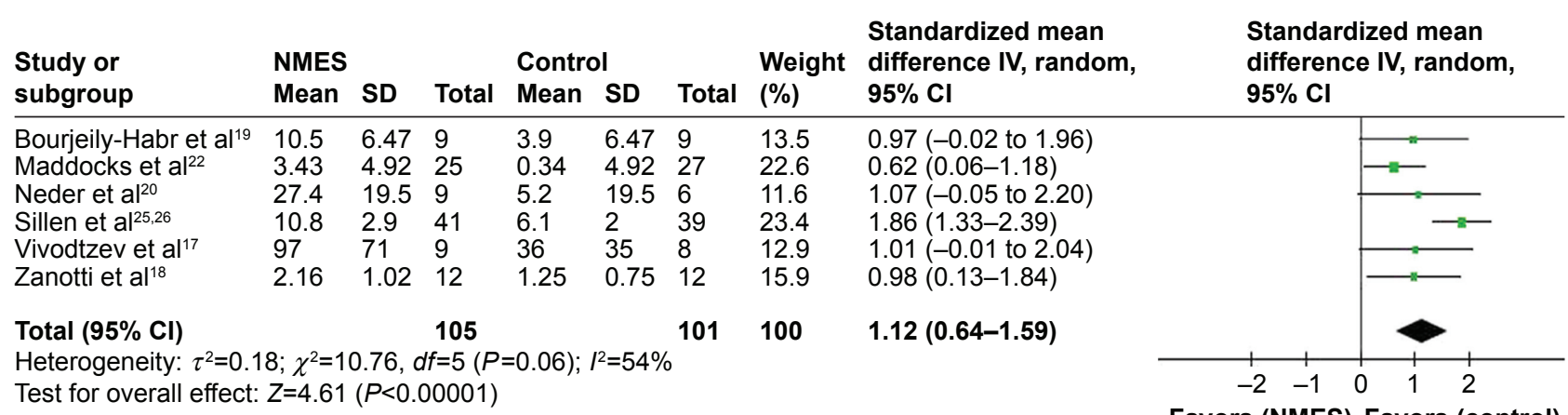

Test for overall effect: $Z=4.61(P<0.00001)$

Favors (NMES) Favors (control)

Figure 5 Meta-analysis of randomized controlled trials evaluating the effects of NMES on quadricep strength.

Abbreviations: NMES, neuromuscular electrical stimulation; SD, standard deviation; IV, inverse variance; Cl, confidence interval.

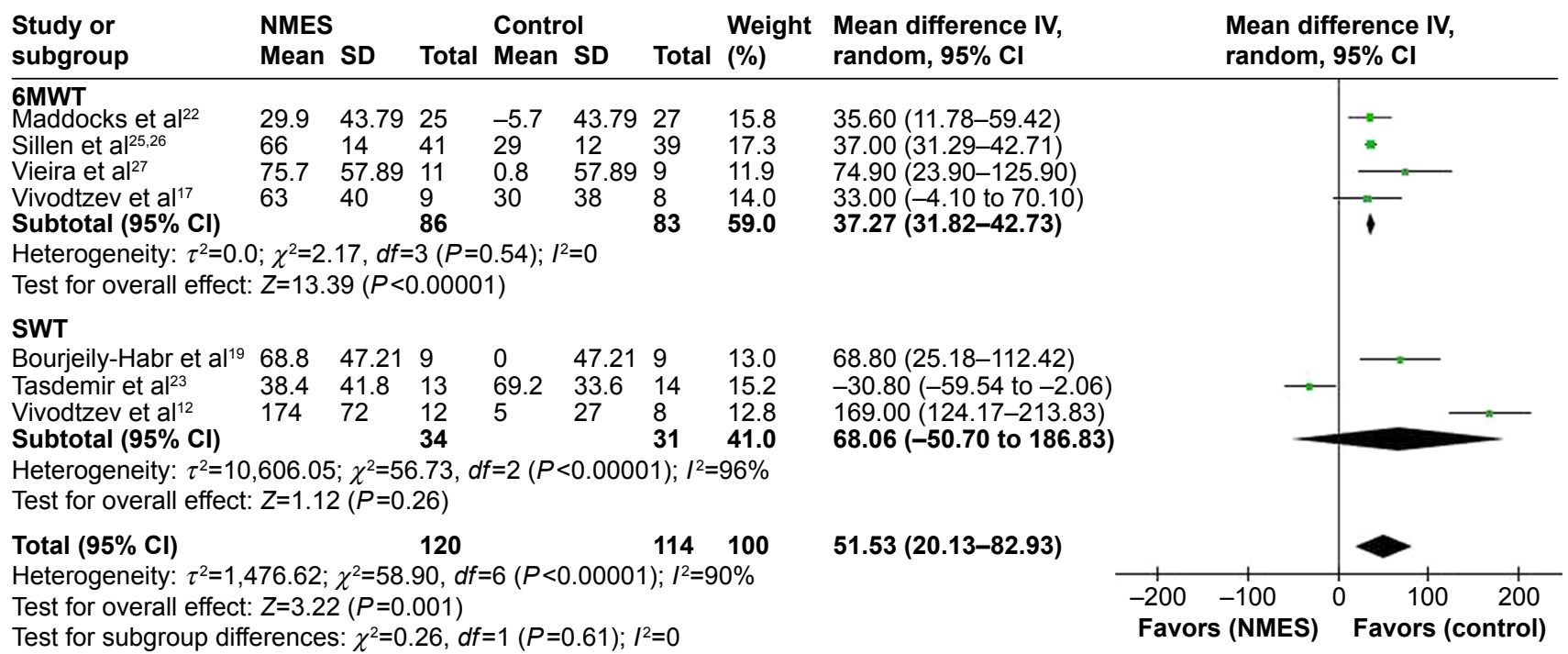

Figure 6 Meta-analysis of randomized controlled trials evaluating the effects of NMES on exercise distance.

Abbreviations: NMES, neuromuscular electrical stimulation; SD, standard deviation; IV, inverse variance; CI, confidence interval; 6MWT, 6-minute walk test; SWT, shuttlewalk test. 


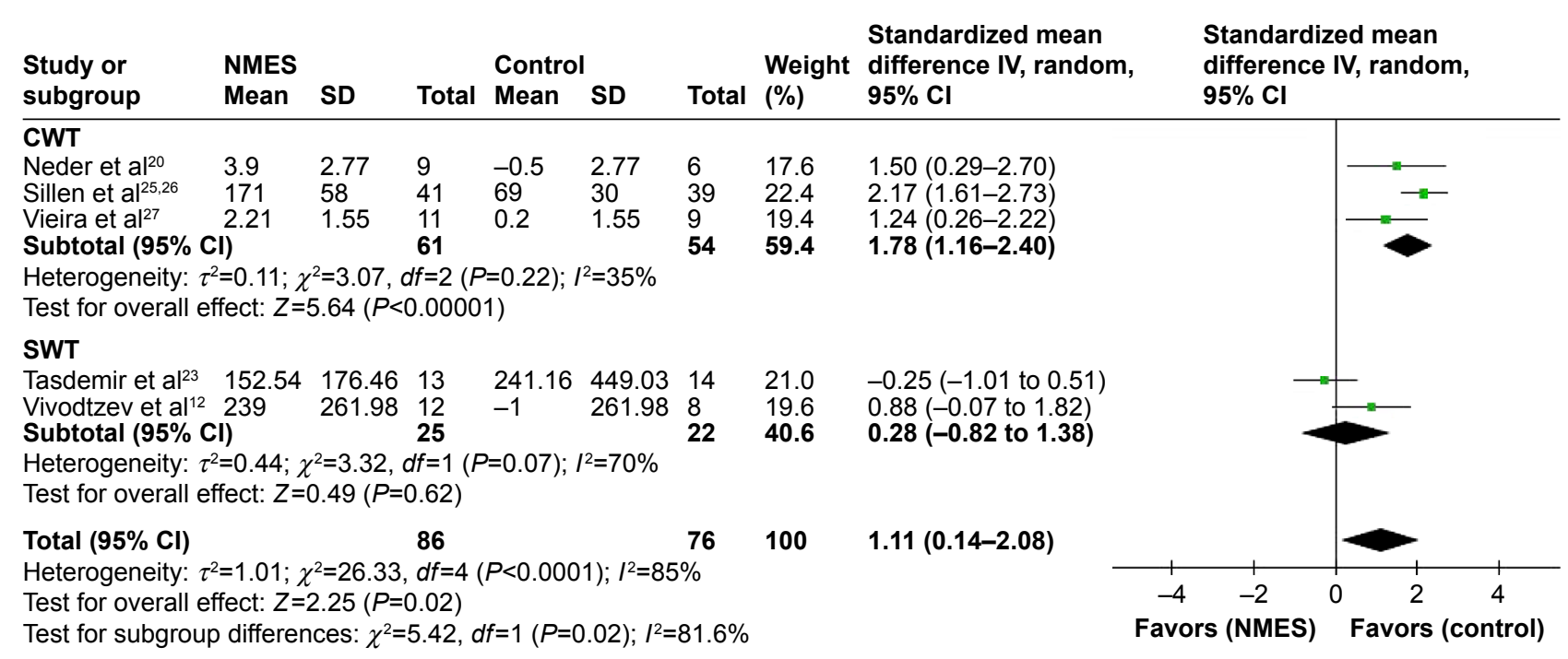

Figure 7 Meta-analysis of randomized controlled trials evaluating the effects of NMES on exercise endurance time.

Abbreviations: NMES, neuromuscular electrical stimulation; SD, standard deviation; IV, inverse variance; CI, confidence interval; CWT, constant-work test; SWT, shuttlewalk test.

Abdellaoui et al. ${ }^{14}$ Intensity might be the most important factor related to the efficacy of NMES on muscle strength. ${ }^{12}$ Actually, stimulus intensity of the pooled studies differed greatly. However, it was defined as "maximal tolerance" in all trials. Therefore, stimulation intensity might be the most suitable and individualized dosage. We should emphasis the role of NMES itself firstly, instead of the dose-dependent response. The aggregate results suggested that regardless of the type of stimulation, significant increases in quadricep strength after NMES are easily achieved, in spite of the lack of an MCID for muscle strength in COPD patients, to assess whether these data are suggestive of clinically meaningful difference. ${ }^{50,51}$ In summary, the overall results proved that quadricep strength was enhanced significantly after NMES.

The methodology of evaluation of exercise capacity may influence the outcome of the study. In Pan et al's review, ${ }^{21}$ only the 6MWT was included in the pooled analysis. In this meta-analysis, three kinds of exercise capacity tests - 6MWT, SWT, and CWT - were included and subgroup analysis conducted. In order to minimize bias, WMD was used to pool walking distance and SMD to pool endurance time. Analogously, we excluded studies ${ }^{14,15,21}$ to avoid variance in entry criteria. The aggregate random effect of NMES on walking distance was $51.53 \mathrm{~m}$ with a $95 \%$ CI of $20.13-82.93$ (Figure 6), exceeding the MCID ranging of 25-33 $\mathrm{m}$ for $6 \mathrm{MWT}$ distance. ${ }^{52}$ However, there was little information on methodological variations in performance of SWT and the lack of an MCID for SWT distance to be compared. The overall pooled SMD data for NMES on endurance time was 1.11 with a $95 \%$ CI of $0.14-2.08$ (Figure 7), indicating that NMES resulted in a beneficial effect on exercise tolerance. We also observed high heterogeneity, which may have come from different SWT methodologies. Incremental SWTs were used in two trials and endurance SWT in another. The sensitivity, responsiveness, and reproducibility of these tests were not the same. ${ }^{53,54}$ In the majority of the cases included, the increasing 6MWT and longer endurance made us consider effect sizes favoring NMES over control in exercise capacity.

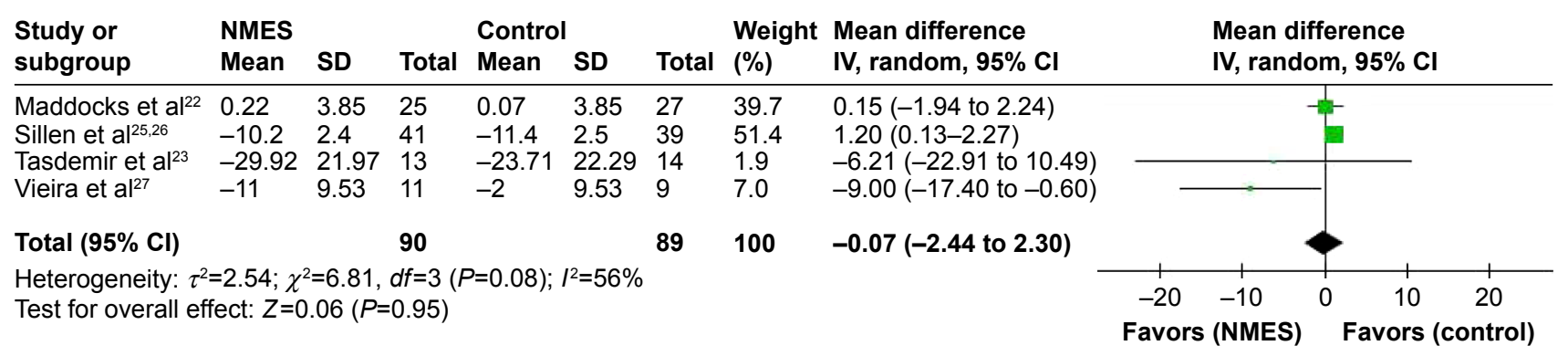

Figure 8 Meta-analysis of randomized controlled trials evaluating the effects of NMES on St George's Respiratory Questionnaire scores.

Abbreviations: NMES, neuromuscular electrical stimulation; SD, standard deviation; IV, inverse variance; Cl, confidence interval. 
However, from the result of our meta-analysis, NMES was not associated with health-related quality of life measured by the SGRQ. The actual value of NMES for healthrelated life quality is thus uncertain, probably due to the fact that the SGRQ is influenced by many other factors. ${ }^{55}$ Further research is required to clarify its place in these outcomes.

This meta-analysis has several limitations. Firstly, the subgroup analysis with small sample size led to insufficient evidence. Secondly, the diversity of measurement could have led to heterogeneity correspondingly. Thirdly, NMES with different parameter settings or programs may lead to different physiological effects and outcomes. Therefore, further research needs to be done to standardize this technique.

In conclusion, NMES appears to be effective in enhancing quadricep strength and exercise capacity in moderate-to-severe COPD patients. Further research is needed to clarify its effect on other outcomes and determine the optimal use of NMES.

\section{Acknowledgments}

The study was supported by the National Natural Science Foundation of China (NSFC, 813111129) and the Science and Technology Project of Guangdong Province (2014A020215033).

\section{Author contributions}

LZ contributed to study conception and design, drafting the submitted article, and revising the draft critically for important intellectual content. RC revised the draft critically for important intellectual content, and provided final approval of the version to be published. XL contributed to acquisition, analysis, and interpretation of data, and drafting the submitted article. LG and BG contributed to acquisition, analysis, and interpretation of data. WW, ZZ, YH, and $\mathrm{XC}$ revised the draft critically for important intellectual content. All authors contributed at all stages of this study, gave final approval of the version to be published, and agree to be accountable for all aspects of the work.

\section{Disclosure}

The authors report no conflicts of interest in this work.

\section{References}

1. Global Initiative for Chronic Obstructive Lung Disease (GOLD). Global Strategy for the Diagnosis, Management, and Prevention of COPD. Bethesda (MD): GOLD; 2016.

2. Narsingam S, Bozarth AL, Abdeljalil A. Updates in the management of stable chronic obstructive pulmonary disease. Postgrad Med. 2015; 127(7):758-770.

3. Teo WS, Tan WS, Chong WF, et al. Economic burden of chronic obstructive pulmonary disease. Respirology. 2012;17(1):120-126.

4. Taivassalo T, Hussain SN. Contribution of the mitochondria to locomotor muscle dysfunction in patients with COPD. Chest. 2016;149(5): $1302-1312$
5. Marciniuk DD, Brooks D, Butcher S, et al. Optimizing pulmonary rehabilitation in chronic obstructive pulmonary disease - practical issues: a Canadian Thoracic Society Clinical practice guideline. Can Respir J. 2010;17(4):159-168.

6. Spruit MA, Troosters T, Trappenburg JC, Decramer M, Gosselink R. Exercise training during rehabilitation of patients with COPD: a current perspective. Patient Educ Couns. 2004;52(3):243-248.

7. Storer TW. Exercise in chronic pulmonary disease: resistance exercise prescription. Med Sci Sports Exerc. 2001;33(7 Suppl):S680-S692.

8. Aquino G, Iuliano E, di Cagno A, et al. Effects of combined training vs aerobic training on cognitive functions in COPD: a randomized controlled trial. Int J Chron Obstruct Pulmon Dis. 2016;11:711-718.

9. Kaymaz D, Ergün P, Demirci E, Demir N. Comparison of the effects of neuromuscular electrical stimulation and endurance training in patients with severe chronic obstructive pulmonary disease. Tuberk Toraks. 2015; 63(1):1-7.

10. Vivodtzev I, Lacasse Y, Maltais F. Neuromuscular electrical stimulation of the lower limbs in patients with chronic obstructive pulmonary disease. J Cardiopulm Rehabil Prev. 2008;28(2):79-91.

11. Acqua A, Dohnert M, Santos L. Neuromuscular electrical stimulation with Russian current for expiratory muscle training in patients with chronic obstructive pulmonary disease. J Phys Ther Sci. 2012;(24):955-959.

12. Vivodtzev I, Debigare R, Gagnon P, et al. Functional and muscular effects of neuromuscular electrical stimulation in patients with severe COPD: a randomized clinical trial. Chest. 2012;141(3):716-725.

13. Giavedoni S, Deans A, McCaughey P, Drost E, MacNee W, Rabinovich RA. Neuromuscular electrical stimulation prevents muscle function deterioration in exacerbated COPD: a pilot study. Respir Med. 2012;106(10):1429-1434

14. Abdellaoui A, Prefaut C, Gouzi F, et al. Skeletal muscle effects of electrostimulation after COPD exacerbation: a pilot study. Eur Respir J. 2011;38(4):781-788.

15. Napolis LM, Dal Corso S, Neder JA, Malaguti C, Gimenes AC, Nery LE. Neuromuscular electrical stimulation improves exercise tolerance in chronic obstructive pulmonary disease patients with better preserved fat-free mass. Clinics (Sao Paulo). 2011;66(3):401-406.

16. Dal Corso S, Napolis L, Malaguti C, et al. Skeletal muscle structure and function in response to electrical stimulation in moderately impaired COPD patients. Respir Med. 2007;101(6):1236-1243.

17. Vivodtzev I, Pepin JL, Vottero G, et al. Improvement in quadriceps strength and dyspnea in daily tasks after 1 month of electrical stimulation in severely deconditioned and malnourished COPD. Chest. 2006; 129(6):1540-1548.

18. Zanotti E, Felicetti G, Maini M, Fracchia C. Peripheral muscle strength training in bed-bound patients with COPD receiving mechanical ventilation: effect of electrical stimulation. Chest. 2003;124(1):292-296.

19. Bourjeily-Habr G, Rochester CL, Palermo F, Snyder P, Mohsenin V. Randomised controlled trial of transcutaneous electrical muscle stimulation of the lower extremities in patients with chronic obstructive pulmonary disease. Thorax. 2002;57(12):1045-1049.

20. Neder JA, Sword D, Ward SA, Mackay E, Cochrane LM, Clark CJ. Home based neuromuscular electrical stimulation as a new rehabilitative strategy for severely disabled patients with chronic obstructive pulmonary disease (COPD). Thorax. 2002;57(4):333-337.

21. Pan L, Guo Y, Liu X, Yan J. Lack of efficacy of neuromuscular electrical stimulation of the lower limbs in chronic obstructive pulmonary disease patients: a meta-analysis. Respirology. 2014;19(1):22-29.

22. Maddocks M, Nolan CM, Man WD, et al. Neuromuscular electrical stimulation to improve exercise capacity in patients with severe COPD: a randomised double-blind, placebo-controlled trial. Lancet Respir Med. 2016;4(1):27-36.

23. Tasdemir F, Inal-Ince D, Ergun P, et al. Neuromuscular electrical stimulation as an adjunct to endurance and resistance training during pulmonary rehabilitation in stable chronic obstructive pulmonary disease. Expert Rev Respir Med. 2015;9(4):493-502.

24. Akar O, Günay E, Ulasli SS, et al. Efficacy of neuromuscular electrical stimulation in patients with COPD followed in intensive care unit. Clin Respir J. Epub 2015 Nov 24 
25. Sillen MJ, Franssen FM, Vaes AW, Delbressine JM, Wouters EF, Spruit MA. Metabolic load during strength training or NMES in individuals with COPD: results from the DICES trial. BMC Pulm Med. 2014; $14: 146$.

26. Sillen MJ, Franssen FM, Delbressine JM, Vaes AW, Wouters EF, Spruit MA. Efficacy of lower-limb muscle training modalities in severely dyspnoeic individuals with COPD and quadriceps muscle weakness: results from the DICES trial. Thorax. 2014;69(6):525-531.

27. Vieira PJ, Chiappa AM, Cipriano GJ, Umpierre D, Arena R, Chiappa GR Neuromuscular electrical stimulation improves clinical and physiological function in COPD patients. Respir Med. 2014;108(4):609-620.

28. Greening NJ, Williams JE, Hussain SF, et al. An early rehabilitation intervention to enhance recovery during hospital admission for an exacerbation of chronic respiratory disease: randomised controlled trial. BMJ. 2014;349:g4315.

29. Hutton B, Catalá-López F, Moher D. [The PRISMA statement extension for systematic reviews incorporating network meta-analysis: PRISMANMA]. Med Clin (Barc). 2016;147(6):262-266. Spanish.

30. Liberati A, Altman DG, Tetzlaff J, et al. The PRISMA statement for reporting systematic reviews and meta-analyses of studies that evaluate health care interventions: explanation and elaboration. PLoS Med. 2009;6(7):e1000100

31. Moher D, Liberati A, Tetzlaff J, Altman DG. Preferred reporting items for systematic reviews and meta-analyses: the PRISMA statement. J Clin Epidemiol. 2009;62(10):1006-1012.

32. Euteneuer S, Windisch W, Suchi S, Köhler D, Jones PW, Schönhofer B. Health-related quality of life in patients with chronic respiratory failure after long-term mechanical ventilation. Respir Med. 2006;100(3): $477-486$

33. Hernandes NA, Wouters EF, Meijer K, Annegarn J, Pitta F, Spruit MA Reproducibility of 6-minute walking test in patients with COPD. Eur Respir J. 2011;38(2):261-267.

34. Eaton T, Young P, Nicol K, Kolbe J. The endurance shuttle walking test: a responsive measure in pulmonary rehabilitation for COPD patients Chron Respir Dis. 2006;3(1):3-9.

35. Arnardóttir RH, Emtner M, Hedenström H, Larsson K, Boman G. Peak exercise capacity estimated from incremental shuttle walking test in patients with COPD: a methodological study. Respir Res. 2006;7:127.

36. Casaburi R. Factors determining constant work rate exercise tolerance in COPD and their role in dictating the minimal clinically important difference in response to interventions. COPD. 2005;2(1):131-136.

37. Higgins JP, Thompson SG, Deeks JJ, Altman DG. Measuring inconsistency in meta-analyses. BMJ. 2003;327(7414):557-560.

38. Furlan AD, Imamura M, Dryden T, Irvin E. Massage for low back pain: an updated systematic review within the framework of the Cochrane Back Review Group. Spine (Phila Pa 1976). 2009;34(16):1669-1684.

39. Furlan AD, Pennick V, Bombardier C, van Tulder M. 2009 Updated method guidelines for systematic reviews in the Cochrane Back Review Group. Spine (Phila Pa 1976). 2009;34(18):1929-1941.

40. Sillen MJ, Wouters EF, Franssen FM, Meijer K, Stakenborg KH, Spruit MA. Oxygen uptake, ventilation, and symptoms during lowfrequency versus high-frequency NMES in COPD: a pilot study. Lung. 2011;189(1):21-26.
41. Sillen MJ, Speksnijder CM, Eterman RM, et al. Effects of neuromuscular electrical stimulation of muscles of ambulation in patients with chronic heart failure or COPD: a systematic review of the Englishlanguage literature. Chest. 2009;136(1):44-61.

42. Roig M, Reid WD. Electrical stimulation and peripheral muscle function in COPD: a systematic review. Respir Med. 2009;103(4):485-495.

43. Sillen MJ, Janssen PP, Akkermans MA, Wouters EF, Spruit MA. The metabolic response during resistance training and neuromuscular electrical stimulation (NMES) in patients with COPD, a pilot study. Respir Med. 2008;102(5):786-789.

44. Jones AY, Ngai SP, Hui-Chan CW, Yu HP. Acute effects of Acu-TENS on FEV1 and blood $\beta$-endorphin level in chronic obstructive pulmonary disease. Altern Ther Health Med. 2011;17(5):8-13.

45. Wen Q, Li N, Yu PM. [Randomized controlled trial on the effect of transcutaneous electrical nerve stimulation at dingchuan (EX-B1) on the pulmonary function of patients with COPD at acute stage]. Zhongguo Zhen Jiu. 2011;31(2):97-100. Chinese.

46. Ngai SP, Jones AY, Hui-Chan CW, Ko FW, Hui DS. Effect of 4 weeks of Acu-TENS on functional capacity and $\beta$-endorphin level in subjects with chronic obstructive pulmonary disease: a randomized controlled trial. Respir Physiol Neurobiol. 2010;173(1):29-36.

47. Lau KS, Jones AY. A single session of Acu-TENS increases FEV1 and reduces dyspnoea in patients with chronic obstructive pulmonary disease: a randomised, placebo-controlled trial. Aust J Physiother. 2008; 54(3):179-184.

48. Guyatt GH, Oxman AD, Vist GE, et al. GRADE: an emerging consensus on rating quality of evidence and strength of recommendations. BMJ. 2008;336(7650):924-926.

49. Atkins D, Eccles M, Flottorp S, et al. Systems for grading the quality of evidence and the strength of recommendations I: critical appraisal of existing approaches. BMC Health Serv Res. 2004;4(1):38.

50. Wouters EF. Minimal clinically important differences in COPD: body mass index and muscle strength. COPD. 2005;2(1):149-155.

51. Beaton DE, Bombardier C, Katz JN, et al. Looking for important change/differences in studies of responsiveness. J Rheumatol. 2001; 28(2):400-405.

52. Singh SJ, Puhan MA, Andrianopoulos V, et al. An official systematic review of the European Respiratory Society/American Thoracic Society: measurement properties of field walking tests in chronic respiratory disease. Eur Respir J. 2014;44(6):1447-1478.

53. Revill SM, Noor MZ, Butcher G, Ward MJ. The endurance shuttle walk test: an alternative to the six-minute walk test for the assessment of ambulatory oxygen. Chron Respir Dis. 2010;7(4):239-245.

54. Revill SM, Morgan MD, Singh SJ, Williams J, Hardman AE. The endurance shuttle walk: a new field test for the assessment of endurance capacity in chronic obstructive pulmonary disease. Thorax. 1999;54(3): 213-222.

55. Henoch I, Strang S, Löfdahl CG, Ekberg-Jansson A. Health-related quality of life in a nationwide cohort of patients with COPD related to other characteristics. Eur Clin Respir J. 2016;3:31459.
International Journal of COPD

\section{Publish your work in this journal}

The International Journal of COPD is an international, peer-reviewed journal of therapeutics and pharmacology focusing on concise rapid reporting of clinical studies and reviews in COPD. Special focus is given to the pathophysiological processes underlying the disease, intervention programs, patient focused education, and self management protocols.

\section{Dovepress}

This journal is indexed on PubMed Central, MedLine and CAS. The manuscript management system is completely online and includes a very quick and fair peer-review system, which is all easy to use. Visit http://www.dovepress.com/testimonials.php to read real quotes from published authors. 